\title{
Green Synthesis and Antibacterial Properties of Silver Nanoparticles of Lawsonia inermis, Rhamnus frangula, Camellia sinensis and Thymus vulgaris Extracts
}

\author{
Sahar Khamees Aldosary ${ }^{1}$ and Soheir N. Abd El-Rahman ${ }^{2 *}$ \\ ${ }^{1}$ Department of Biology, College of Science, Imam Abdulrahman Bin Faisal University, P.O. Box 1982, Dammam \\ 31441, Saudi Arabia. ${ }^{2}$ Crops Technology Research Department, Food Technology Research Institute, Agricultural \\ Research Center, Giza, Egypt.
}

\begin{abstract}
Metal nanoparticles are used often in medicine; however, they are associated with collateral damage. Therefore, an alternative source of nanoparticles, for example plant extracts, which have been used in folk medicine, is required that is both effective and eco-friendly. In this study, we used Lawsonia inermis, Rhamnus fsrangula, Camellia sinensis, and Thymus vulgaris to prepare silver nitrate nanoparticles (AgNPs). The nanoparticles were differentiated by UV-Vis spectroscopy and transmission electron microscopy. Further, the antibacterial and antifungal activity of each AgNPs preparation was examined against different species of microorganisms. A change in color of the plant extracts was considered to indicate formation of AgNPs. AgNPs synthesized using these plant extracts showed significant antimicrobial activity against selected strains of bacteria and fungi. Therefore, these AgNPs prepared using plant extracts are effective and safe for use against these microbes. They also offer important advantages over commercial antibiotics and may prevent the risk of emergence of antibiotic-resistant bacterial strains.
\end{abstract}

Keywords: Silver nanoparticles, Medicinal plants, Antibacterial, Inhibition zone, UV-VIS spectroscopy.

\footnotetext{
*Correspondence: soheirkenawy@yahoo.com

(Received: 03 June 2019; accepted: 22 June 2019)

Citation: Sahar Khamees Aldosary and Soheir N. Abd El-Rahman, Green Synthesis and Antibacterial Properties of Silver Nanoparticles of Lawsonia inermis, Rhamnus frangula, Camellia sinensis and Thymus vulgaris Extracts, J Pure Appl Microbiol., 2019; 13(2):1279-1284. doi: 10.22207/JPAM.13.2.71

C The Author(s) 2019. Open Access. This article is distributed under the terms of the Creative Commons Attribution 4.0 International License which permits unrestricted use, sharing, distribution, and reproduction in any medium, provided you give appropriate credit to the original author(s) and the source, provide a link to the Creative Commons license, and indicate if changes were made.
} 


\section{INTRODUCTION}

Nanotechnology is primarily concerned with the synthesis of nanoparticles of variable shape, chemical composition, size, and controlled dispersity, and may be used for human benefits. Physical and chemical methods are used to successfully produce well-defined and pure nanoparticles, but these methods are potentially hazardous to the environment and also very expensive $^{1-3}$. Different methods have been developed to produce nanoparticles, the most popular being chemical approaches; however, it is not feasible to avoid the use of toxic chemicals in the synthesis protocol of some chemical methods. Since the application of noble nanoparticles, such as platinum, silver, and gold, to human contact on a large scale, there has been an increasing need to synthesize nanoparticles without using toxic chemicals and to develop environmental-friendly synthesis processes ${ }^{4}$.

Researchers have long recognized that silver has an inhibitory effect on microorganisms in general and many bacterial strains normally encountered in industrial and medical processes ${ }^{5}$. Silver and silver nanoparticles (AgNPs) most commonly find applications in the medical industry ${ }^{6}$. In recent years, biological methods for nanoparticle synthesis using enzymes, plants or plant extracts, and microorganisms have emerged as eco-friendly alternatives to physical and chemical methods ${ }^{7-9}$. Nanoparticle synthesis using plants can be useful in other biological processes by eliminating the complex process of preserving cell cultures ${ }^{10,11}$. Recent approaches to green chemistry using plant extracts for the synthesis of AgNPs have become a major focus owing to their potential applications and stability and the simplicity of their associated procedures.
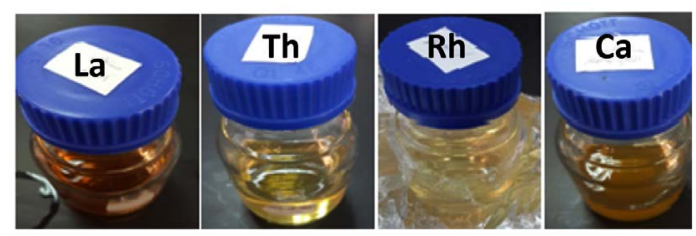

Fig. 1. (La) Lawsonia inermis, (Th) Thymus vulgaris, (Rh) Rhamnus frangula and (Ca) Camellia sinensis before added the leaf extracts with aqueous solution of silver nitrate
Plant materials such as root, bark, leaf, callus, fruit, and fruit peel have been used in many studies on nanoparticle synthesis in recent years ${ }^{12,13}$. Therefore, the aim of this study was to synthesize AgNPs by reducing silver ions with aqueous leaf extracts from Camellia sinensis, Rhamnus frangula, Thymus vulgaris, and Lawsonia inermis. Further, we aimed to evaluate the antimicrobial effect of the synthesized nanoparticles against different bacterial and fungal species. These plants were chosen because they are often used in folk and popular medicine for the treatment of many diseases and for their anti-microbial activity.

Samples of healthy $C$. sinensis, $R$. frangula, $T$. vulgaris, and $L$. inermis leaves were collected from a local market in Dammam, Saudi Arabia. After transport to the lab, the samples were stored at $-20^{\circ} \mathrm{C}$ until use.

\section{MATERIALS AND METHODS}

\section{Plant extraction and AgNPs biosynthesis}

To remove contaminants and particles of adherent dust from the samples, leaves were initially rinsed with running tap water, followed by a second wash step with sterile distilled water. Four grams of each leaf sample was cut into small pieces, and then boiled for $5 \mathrm{~min}$ in $20 \mathrm{~mL}$ distilled water. The samples were then filtered through filter paper (Whatman No. 1). Ten milliliters of the filtrate was mixed with $90 \mathrm{~mL}$ of $1 \mathrm{mM} \mathrm{AgNO}_{3}$ and incubated overnight in the dark to avoid photoactivation of silver nitrate. A control sample was prepared without adding plant extracts. For the synthesis of nanoparticles was followed a similar

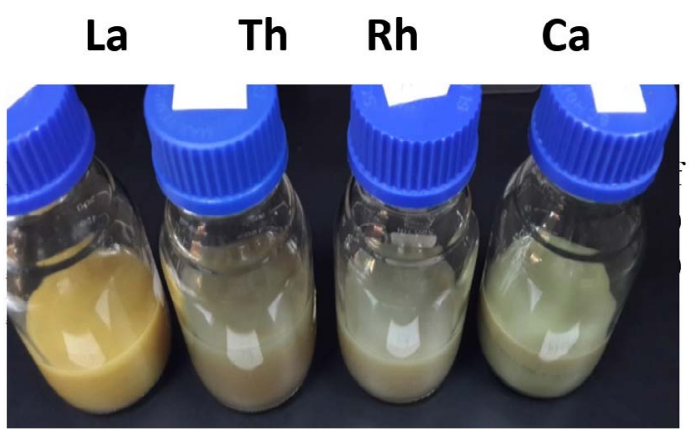

Fig. 2. The changes of color after added the leaf extracts to aqueous solution of silver nitrate (La) Lawsonia inermis, (Th) Thymus vulgaris, (Rh) Rhamnus frangula and (Ca) Camellia sinensis. 
procedure by using centrifuged leaf extract ${ }^{14}$. AgNPs characterization

A UV-Vis spectrometer was used to confirm the synthesis of the AgNPs using the plant extracts by determining the absorption peak at $200-700 \mathrm{~nm}$ at regular intervals. To remove impurities, the reaction mixture was centrifuged for $10 \mathrm{~min}$ at $10,000 \mathrm{rpm}$ and the pellet was washed three times and then resuspended in sterile distilled water.

Transmission electron microscopy (TEM)

Transmission electron microscope (FEI,

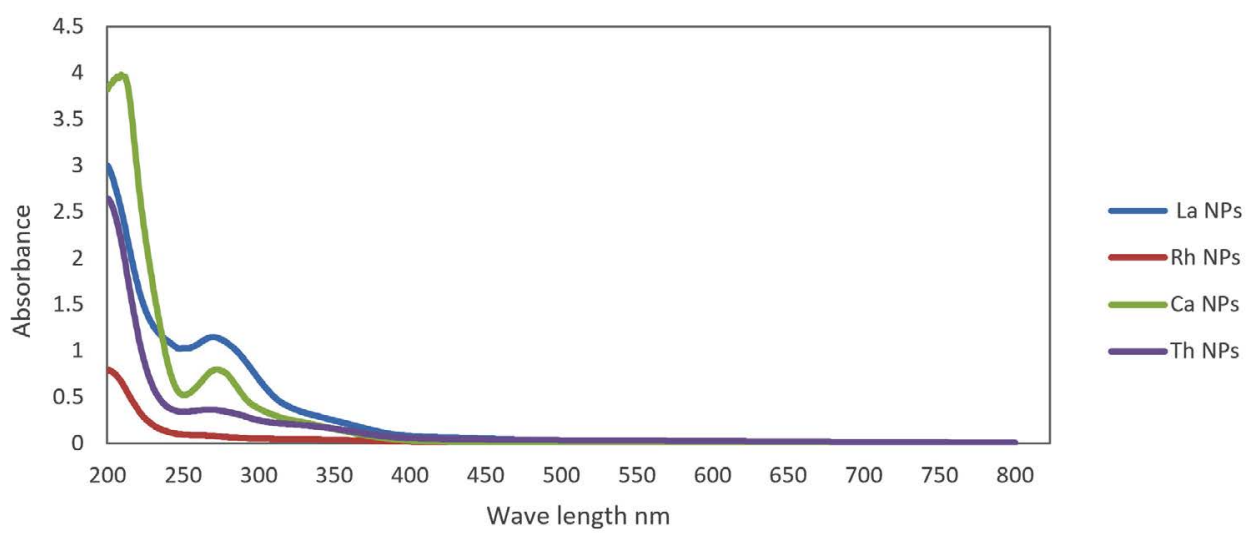

Fig. 3. UV-Vis absorbance of La, Rh, Ca and Th silver nanoparticles.

a

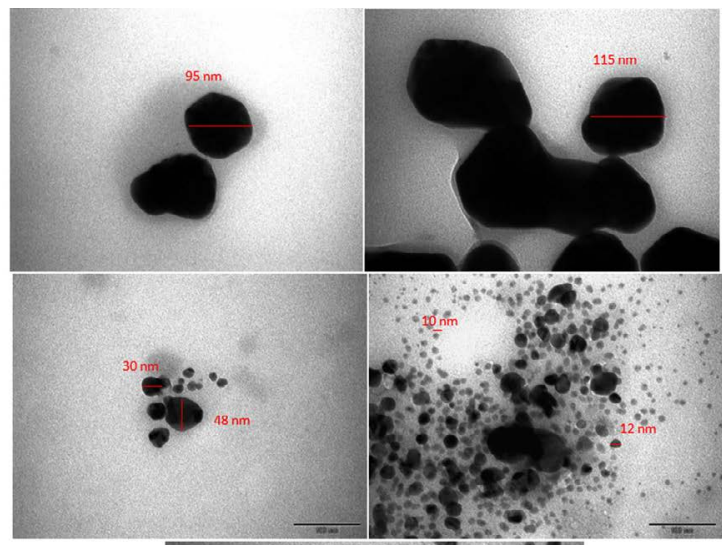

c

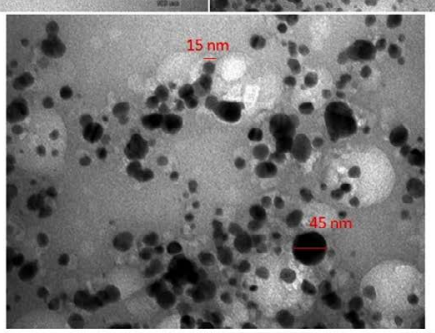

d

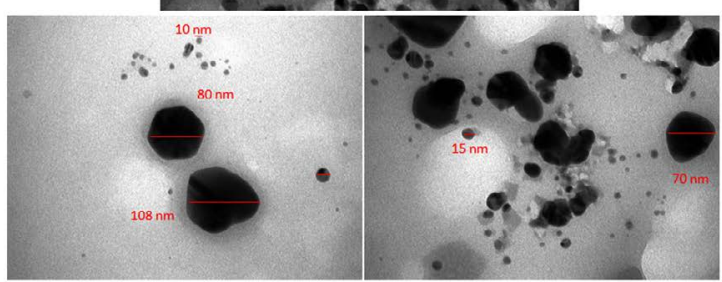

Fig 4. TEM images of a) La, b)Rh, c) Ca and d) Th silver nanoparticles. 
TEM, Czech Republic working accelerating voltage was $80 \mathrm{Kv}$ ) was used to analyze the nanoparticle size and surface morphology.

Analysis of antibacterial activity of AgNPs

Clinical samples were collected from the King Fahad University Hospital microbiology laboratory, Al Khobar.

In vitro antibacterial activity was determined for the AgNPs synthesized using each leaf extract. First, the dried AgNPs were weighed and dissolved in sterile distilled water (C. sinensis extract-AgNPs, $1243.6 \mathrm{mg} / 10 \mathrm{~mL}$; $R$. frangula extract-AgNPs, $914.8 \mathrm{mg} / 10 \mathrm{~mL}$; T. vulgaris extractAgNPs, $675.1 \mathrm{mg} / 10 \mathrm{~mL}$; and $L$. inermis extractAgNPs, $1094.6 \mathrm{mg} / 10 \mathrm{~mL}$ ), and immediately used. The following 10 human pathogens were used for assaying the antimicrobial activity of the AgNPs: Streptococcus pyogenes, Candida albicans, Enterococcus faecalis, Enterobacter cloacae, methicillin-resistant Staphylococcus aureus (MRSA) ATCC, three strains of Klebsiella pneumoniae (MDR), Escherichia coli, four strains of Pseudomonas aeruginosa (MDR), Klebsiella pneumoniae, and Acinetobacter (HDR). A single colony was inoculated into nutrient broth and incubated overnight. Then, the turbidity was adjusted to $0.5 \mathrm{McF}$ arland standard for the inocula ${ }^{15}$. Next, the inocula were spread onto nutrient agar plates using a swab, and $25 \mu \mathrm{L}$ AgNPs (approximately $125 \mu \mathrm{g}$ ) was added into the well.
$\mathrm{AgNO}_{3}(1 \mathrm{mM})$, leaf extracts, and ciprofloxacin (commercial antibiotic) were also added as standard to other wells as positive and negative controls, respectively. The plates were incubated for $24 \mathrm{~h}$ at $37^{\circ} \mathrm{C}$ and the inhibition zone was measured and expressed in millimeters. Data for each strain were collected from three independent experiments repeated twice ${ }^{16}$.

\section{RESULTS AND DISCUSSION \\ UV-Vis spectrophotometric measurements for AgNPs}

In our study, we used an extracellular biosynthesis method to prepare AgNPs using leaf extracts. The color of the extracts changed to brown (Fig. 2) after the leaf extracts were added to a solution of silver nitrate; this indicated that AgNPs were synthesized, which was attributed to surface plasmon vibrations excitation with the AgNPs ${ }^{17,18}$. The results of UV-Vis spectrophotometric measurements showed a strong absorption peak at 220 to $300 \mathrm{~nm}$ for $R$. frangula extract-AgNPs, when using. For $L$. inermis extractAgNPs, the peak absorption was observed at 210 to $370 \mathrm{~nm}$; for $C$. sinensis extract-AgNPs, it was observed at 240 to $310 \mathrm{~nm}$; and for T. vulgaris extract-AgNPs, it was observed at 210 to $350 \mathrm{~nm}$ (Fig. 3). UV-Vis analysis between 200 to $600 \mathrm{~nm}$ showed maximum absorbance at $440 \mathrm{~nm}$ for $L$. inermis extract-AgNPs ${ }^{19}$. An absorbance peak

Table 1. Antimicrobial activity of La, Rh, Ca and Th silver nanoparticles

\begin{tabular}{|c|c|c|c|c|c|c|}
\hline \multirow[b]{2}{*}{ Isolates } & \multicolumn{5}{|c|}{ Inhibition zone (mm) } & \multirow[b]{2}{*}{$\begin{array}{c}\text { Control* } \\
\text {-ve }\end{array}$} \\
\hline & $\begin{array}{l}\text { Lawsonia } \\
\text { inermis }\end{array}$ & $\begin{array}{l}\text { Rhamnus } \\
\text { Frangula }\end{array}$ & $\begin{array}{l}\text { Camellia } \\
\text { sinensis }\end{array}$ & $\begin{array}{l}\text { Thymus } \\
\text { vulgaris }\end{array}$ & $\begin{array}{l}\text { Control* } \\
+ \text { +ve }\end{array}$ & \\
\hline Streptococcus pyogens & $\mathrm{R}$ & $\mathrm{R}$ & $\mathrm{R}$ & $\mathrm{R}$ & $\mathrm{R}$ & $\mathrm{R}$ \\
\hline Candida albicans & $10 \mathrm{~mm}$ & $\mathrm{R}$ & $\mathrm{R}$ & $5 \mathrm{~mm}$ & $11 \mathrm{~mm}$ & $21.5 \mathrm{~mm}$ \\
\hline Enterofecalis & $4 \mathrm{~mm}$ & $\mathrm{R}$ & $\mathrm{R}$ & $4 \mathrm{~mm}$ & $14 \mathrm{~mm}$ & $14 \mathrm{~mm}$ \\
\hline E. coli & $7 \mathrm{~mm}$ & $\mathrm{R}$ & $\mathrm{R}$ & $13 \mathrm{~mm}$ & $4 \mathrm{~mm}$ & $\mathrm{R}$ \\
\hline Entero cloacae & $\mathrm{R}$ & $\mathrm{R}$ & $\mathrm{R}$ & $\mathrm{R}$ & $11 \mathrm{~mm}$ & $13 \mathrm{~mm}$ \\
\hline Klebsiella pneumonia & $\mathrm{R}$ & $4 \mathrm{~mm}$ & $3 \mathrm{~mm}$ & $\mathrm{R}$ & $4.5 \mathrm{~mm}$ & $5 \mathrm{~mm}$ \\
\hline MRSA ATCC & $7 \mathrm{~mm}$ & $6 \mathrm{~mm}$ & $\mathrm{R}$ & $6 \mathrm{~mm}$ & $32 \mathrm{~mm}$ & $8 \mathrm{~mm}$ \\
\hline $\begin{array}{l}\text { Klebsiella pneumoniae } \\
\text { (MDR) }\end{array}$ & $\mathrm{R}$ & $\mathrm{R}$ & $\mathrm{R}$ & $\mathrm{R}$ & $8 \mathrm{~mm}$ & $\mathrm{R}$ \\
\hline $\begin{array}{l}\text { Pseudomonas aeuroginosa } \\
\text { MDR }\end{array}$ & $4 \mathrm{~mm}$ & $4 \mathrm{~mm}$ & $28 \mathrm{~mm}$ & $36 \mathrm{~mm}$ & $32 \mathrm{~mm}$ & $9 \mathrm{~mm}$ \\
\hline Acinobactor HDR & $\mathrm{R}$ & $\mathrm{R}$ & $\mathrm{R}$ & $30 \mathrm{~mm}$ & $15 \mathrm{~mm}$ & $20 \mathrm{~mm}$ \\
\hline${ }^{*} \mathrm{R}=$ Resistant & \multicolumn{2}{|c|}{${ }^{*}$ Control $+v e=$ Ciprofloyin } & \multicolumn{2}{|c|}{${ }^{*}$ Control $-\mathrm{ve}=\mathrm{AgNo}_{3}$} & & \\
\hline
\end{tabular}


of 427-437 $\mathrm{nm}$ was previously observed for $C$. sinensis extract-AgNPs, using UV-Vis spectrophotometer ${ }^{20}$.

\section{Transmission electron microscopy (TEM)}

TEM images of the plant extract-AgNPs are shown in Fig. 4. The AgNPs were spherical with varying size as follows: $L$. inermis, $95-115 \mathrm{~nm}$ (Fig 4.a); R. frangula, 10-48 nm (Fig 4.b); C. sinensis, 15$45 \mathrm{~nm}$ (Fig 4.c); and T. vulgaris, 10-108 nm (Fig 4.d). T. vulgaris extract-AgNPs were previously reported to have a spherical shape and average particle size of approximately $30-50 \mathrm{~nm}^{21}$. TEM micrographs of L. inermis extract-AgNPs in this study indicated that the particles have a spherical morphology and are well segregated with a mean diameter of $18 \mathrm{~nm}$. Individually separated lattice fringes were clearly visible and well-ordered as revealed by TEM. The results confirmed the formation of spherical, polycrystalline, stable, and uniform AgNPs using leaf extract of $L$. inermis ${ }^{18}$.

\section{Antimicrobial activity}

Table 1 shows the antimicrobial activity of the plant extract-AgNPs. S. pyogenes was resistant to all of the plant extract-AgNPs and also resistant to ciprofloxacin. Similarly, K. pneumoniae (MDR) was resistant to all the plant extract-AgNPs, as well as to $\mathrm{AgNO}_{3}$, but was inhibited by ciprofloxacin, with an inhibition zone diameter of $8 \mathrm{~mm}$. The effect of $T$. vulgaris extract-AgNPs against $E$. coli, $P$. aeruginosa (MDR), and Acinetobacter (HDR) was stronger than that of AgNPs synthesized using the other extracts, and positive or negative controls. L. inermis extract-AgNPs were more effective against $C$. albicans than $T$. vulgaris extract-AgNPs (10 $\mathrm{mm}$ and $5 \mathrm{~mm}$ inhibition zone diameters, respectively). Conversely, T. vulgaris extract-AgNPs were more effective against $E$. coli than $L$. inermis extract-AgNPs (13 $\mathrm{mm}$ and $7 \mathrm{~mm}$ inhibition zone diameters, respectively). Additionally, all the plant extract-AgNPs were able to inhibit the growth of $P$. aeruginosa (MDR). K. pneumoniae (MDR) and E. cloacae were resistant to all the plant extractAgNPs.

The inhibition zone diameters for $L$. inermis extract-AgNPs against E. coli, P. aeruginosa, Bacillus subtilis, and Proteus vulgaris were 12 $\mathrm{mm}, 11 \mathrm{~mm}, 13 \mathrm{~mm}$, and $9 \mathrm{~mm}$, respectively, whereas the average inhibition zone diameter for amoxicillin was $20 \mathrm{~mm}$. AgNPs synthesized using $L$. inermis extract have been shown to have maximum antibacterial activity against $B$. subtilis ${ }^{22}$. In this study, $L$. inermis extract-AgNPs demonstrated maximum inhibition against $B$. subtilis $(21 \mathrm{~mm}), S$. aureus (22 mm), E. coli (20 mm), K. pneumoniae $(21 \mathrm{~mm})$, and $P$. aeruginosa $(17 \mathrm{~mm})$. Ciprofloxacin antibiotic disc inhibition zone diameters were 22 $\mathrm{mm}, 0 \mathrm{~mm}, 30 \mathrm{~mm}, 0 \mathrm{~mm}, 30 \mathrm{~mm}$, and $28 \mathrm{~mm}$ for S. pneumoniae, E. coli, S. aureus, P. aeruginosa, $B$. subtilis, and $K$. pneumoniae, respectively. The extract of $R$. californica leaves was the most active among the three extracts, whereby the strongest effect was noted on the only antibiotic-resistant strain tested, $\mathrm{MRSA}^{23}$. C. sinensis extract-AgNPs have also shown potent antimicrobial activity against pathogenic bacteria ${ }^{20}$.

\section{CONCLUSION}

In this study, we attempted bio-reduction of silver ions using extracts of medicinal plants and tested the antimicrobial activity of the AgNPs formed. We noted a change in the color of the plant extracts, which was considered to indicate the formation of AgNPs. We noted good antimicrobial activity of these AgNPs against different microorganisms. T. vulgaris extractAgNPs were more effective than AgNPs prepared using other extracts, and the positive or negative controls, against E. coli, P. aeruginosa (MDR), and Acinetobacter (HDR). L. inermis extract-AgNPs were more effective against $C$. albicans than $T$. vulgaris extract-AgNPs. In contrast, $T$. vulgaris extract-AgNPs were more effective against $E$. coli than $L$. inermis extract-AgNPs. We conclude that AgNPs synthesized using medicinal plant extracts have a significant antifungal effect, and therefore have the potential to be widely used in the manufacture of antimicrobial drugs.

\section{ACKNOWLEDGEMENTS}

We gratefully acknowledge for the assistance of Nouf M. Al-Romihi, Microbiology supervisor in King Fahad University Hospital, Imam Abdulrahman Bin Faisal University and Dr. Sultan Akhtar, in Electron Microscopy Unit, Institute for Research and Medical Consultations, Imam Abdulrahman Bin Faisal University.

\section{CONFLICT OF INTEREST}

The authors declare that there is no conflict of interest. 


\section{AUTHORS' CONTRIBUTION}

All authors have made substantial, direct and intellectual contribution to the work and approved it for publication.

\section{FUNDING}

None

\section{DATA AVAILABILITY}

All datasets generated or analyzed during this study are included in the manuscript.

\section{ETHICS STATEMENT}

This article does not contain any studies with human participants or animals performed by any of the authors.

\section{REFERENCES}

1. Sastry M., Ahmad A., Khan M. I. and KumarR. Microbial nanoparticle production, in Nano-biotechnology, ed. by Niemeyer C. M. and Mirkin C. A. Wiley-VCH, Weinheim, 2004, 126

2. Bhattacharya D., and Rajinder G., Crit Rev. Biotechnol., 2005; 25: 199.

3. Mohanpuria P., Rana N. K., Yadav S.K., J. Nanopart Res. 2008; 10: 507.

4. Divya T. RAJ Yamuna K. Ayisha S. Joseph P. Synthesis of silver phyto nanoparticles and their antibacterial efficacy, 2010; Dig J Nanomat Biostruct 5(1): 185-189.

5. Jiang H. , Manolache S. , Wong A. C. L. , Denes F. S. Plasma enhanced deposition of silver nano-particles onto polymer and metal surfaces for the generation of antimicrobial characteristics. J. Appl. Polym. Sci. , 2004; 93: 1411-1422

6. Becker R. O. Silver ions in the treatment of local infections. Met. Based Drugs, 1999; 6: 297-300

7. Klaus T., Joerger R., Olsson E., Granqvist C-G Silverbased crystalline nanoparticles, microbially fabricated. Proc. Natl. Acad. Sci. USA, 96: 13611-13614

8. Konishi Y. , Ohno K. , Saitoh N., Nomura T. , Nagamine S., Hishida H. , Takahashi Y., Uruga T. Bioreductive deposition of platinum nanoparticles on the bacterium Shewanella algae. J. Biotechnol., 2007; 128: 648-653

9. Nair B., Pradeep T. Coalescense of nanoclusters and formationof submicron crystallites assisted by Lactobacillus strains. Cryst. Growth Des., 2002; 2: 293-298

10. Willner I., Baron R., Willner B. Growing metal nanoparticlesby enzymes. Adv. Mater., 2006; 18: 1109-1120

11. Shankar S. S. , Rai A. , Ahmad A. , Sastry M. Rapid synthesis of $\mathrm{Au}, \mathrm{Ag}$, and bimetallic $\mathrm{Au}$ core $\mathrm{Ag}$ shell nanoparticles using Neem (Azadirachta indica) leaf broth. J. Colloid. Interface Sci. , 2004; 275: 496-502

12. V. Gopinath, D. Mubarak Ali, S. Priyadarshini, N. Meera
Priyadharsshini, N. Thajuddin, P. Velusamy, Colloids Surf. B., 2012; 96: 69-74.

13. Jeeva K., Thiyagarajan M., Elangovan V., Geetha N., Venkatachalam P: Caesalpinia coriaria leaf extracts mediated biosynthesis of metallic silver nanoparticles and their antibacterial activity against clinically isolated pathogens. Ind. Crop Prod. , 2014, 52: 714-720.

14. Savithramma N., Linga Rao M. , Ankanna S. and Venkateswarlu P. Screening of medicinal plants for effective biogenesis of silver nano particles and efficient anti-microbial activity. International Journal of Pharmaceutical Sciences and Researches, 2012; 3(4): 1141-1148.

15. Kora A.J., Manjusha R., Arunachalam J. Superior bactericidal activity of SDS capped silver nanoparticles: synthesis and characterization. Mater. Sci. Eng. 2009; C29: 2104-2109.

16. N. Savithramma, M. Linga Rao, S. Ankanna and P. Venkateswarlu, Screening of medicinal plants for effective biogenesis of silver nano particles and efficient anti-microbial activity. 3. 4 (Apr. 2012): p1141.

17. Mulvaney P. Surface plasmon spectroscopy of nanosized metal particles. Langmuir., 1996; 12: 788-800.

18. B. Ajitha, Y. Ashok Kumar Reddy, P. Sreedhara Reddy, Y. Suneetha, Hwan-Jin Jeon, Chi Won Ahn. Instant biosynthesis of silver nanoparticles using Lawsonia inermis leaf extract: Innate catalytic, antimicrobial and antioxidant activities. Journal of Molecular Liquids, 2016; 219: 474-481.

19. Dama L.B., Mane P.P., Pathan A.V., Chandarki M. S., Sonawane S.R., Dama S.B., Chavan S. R. Chondekar R. P. and Vinchurkar A. S. Green synthesis of silver nanoparticles using leaf extract of Lawsonia inermis and Psidium guajava and evaluation of their antibacterial activity. Science Research Reporter, 2016; 6(2): 89-95.

20. Varun Kumar, Ridhima Wadhwa, Nitesh Kumar, Pawan Kumar Maurya. A comparative study of chemically synthesized and Camellia sinensis leaf extractmediated silver nanoparticles. Biotech., 2019; 9: 7. https://doi. org/10. 1007/s13205-018-1544-0

21. Suhailah S. Al-Jameel, Suheir N. Abd El-Rahman and Sahar Khamees Aldosary. Comparative study of antimicrobial and antioxidant activity of the of Boswllia (frankincense)and synthesized silver nanoparticles. , Journal of Food, Agriculture and Environment, 2018; 16(1): 20-

22. Husam M. kredy. The effect of $\mathrm{pH}$, Temperature on the green synthesis and biochemical activities of silver nanoparticles from Lawsonia inermis extract. Husam M. kredy et al. J. Pharm. Sci. \& Res., 2018; 10(8): 20222026.

23. Carranza G. Maria, Mary B. Sevigny, Debashree Banerjee and Lacie Fox-Cubley. Antibacterial activity of native California medicinal plant extracts isolated from Rhamnus californica and Umbellularia californica. Ann. Clin. Microbiol. Antimicrob., 2015; 14: 29 DOI 10. 1186/s12941-015-0086-0. 